\section{REFERENCES}

1. Conley J, Lattes R, Orr W. Desmoplastic malignant melanoma (a rare variant of spindle cell melanoma). Cancer 1971;28: 914-936.

2. Posther KE, Selim MA, Mosca PJ, Stanley WE, Johnson JL, Tyler DS, et al. Histopathologic characteristics, recurrence patterns, and survival of 129 patients with Desmoplastic melanoma. Ann Surg Oncol 2006;13:728-739.

3. Lens MB, Newton-Bishop JA, Boon AP. Desmoplastic malig- nant melanoma: a systematic review. Br J Dermatol 2005; 152:673-678.

4. Dalvin LA, Damento GM, Yawn BP, Abbott BA, Hodge DO, Pulido JS. Parkinson disease and melanoma: confirming and reexamining an association. Mayo Clin Proc 2017;92:10701079.

5. Disse M, Reich H, Lee PK, Schram SS. A review of the association between parkinson disease and malignant melanoma. Dermatol Surg 2016;42:141-146.

\title{
A Case of Cutaneous Mycobacterium chelonae Infection Induced by Body Scurbbing
}

\author{
Jee Yon Shin, Dae Hwi Eun, Ji Yeoun Lee, Tae Young Yoon \\ Departments of Dermatology, College of Medicine, Chungbuk National University, Cheongju, Korea
}

\section{Dear Editor:}

A 69-year-old female presented with a 7-month history of multiple variable sized bizarrely shaped ulcers and erosions on the ecchymotic or reddish patches on the neck, chest, and arms (Fig. 1A, B). She had no underlying disease and wasn't taking any medicine which could suppress her own immunity. The lesion originated on the neck, and slowly spread to the chest over a duration of 2 months. After that, it subsequently spread from the chest to the arms over a duration of 3 months. The lesion caused itching and pain. She was treated with antibiotics and topical steroid in local clinics, but her condition had not improved. There was no history of invasive procedure or trauma. The patient's daughter disclosed that she had scrubbed the patient's body daily with an abrasive scrub towel while bathing her. Skin biopsy was performed on her neck and right forearm. Histopathologic findings showed granulomatous inflammation on the dermis and subcutaneous tissue on the both specimens (Fig. 2A, B). Numerous acid-fast bacilli were detected by acid-fast bacilli stain (Fig. 2C) and a polymerase chain reaction revealed Mycobacterium chelonae. The patient was treated with clarithromycin for 6 months, and the lesion has since almost healed.

Atypical mycobacterial infection is caused by mycobacteria, other than Mycobacterium tuberculosis and Мyсоbacterium leprae ${ }^{1}$. Atypical mycobacteria are present in many environmental areas, such as wet soil, water, and in dairy products. Tap water is considered the major reservoir, for nontuberculous mycobacteria pathogens in humans $^{2}$.

M. chelonae is a rapid growing mycobacteria, isolated

Received April 10, 2019, Revised May 21, 2019, Accepted for publication May 21, 2019

Corresponding author: Tae Young Yoon, Department of Dermatology, College of Medicine, Chungbuk National University, 1 Chungdae-ro, Seowon-gu, Cheongju 28644, Korea. Tel: 82-43-269-6369, Fax: 82-43-266-1698, E-mail: tyyoon@chungbuk.ac.kr ORCID: https://orcid.org/0000-0001-6947-1853

This is an Open Access article distributed under the terms of the Creative Commons Attribution Non-Commercial License (http://creativecommons.org/licenses/by-nc/4.0) which permits unrestricted non-commercial use, distribution, and reproduction in any medium, provided the original work is properly cited.

Copyright $($ The Korean Dermatological Association and The Korean Society for Investigative Dermatology 

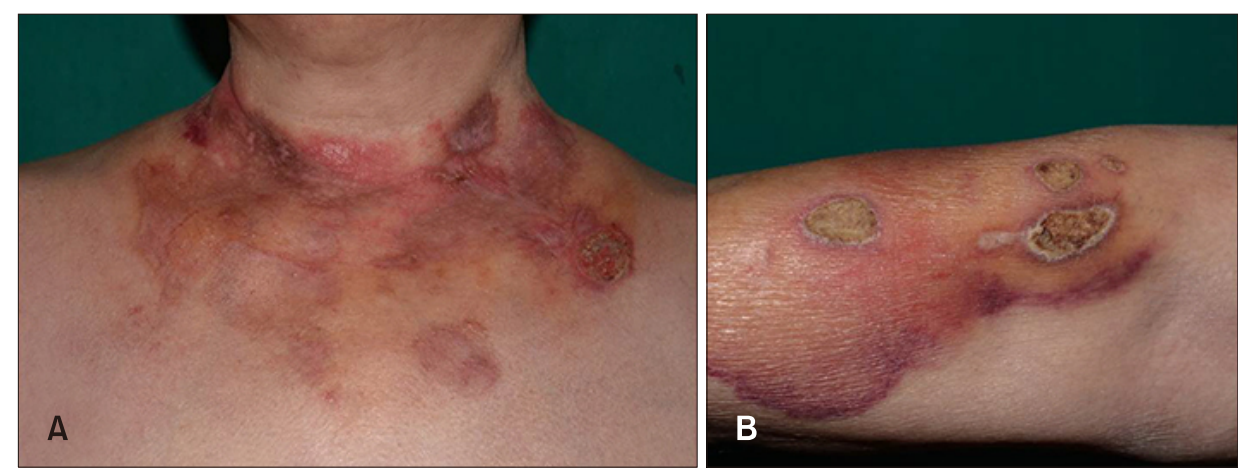

Fig. 1. (A, B) Multiple variable sized bizarrely shaped ulcers and erosions on the ecchymotic or reddish patches on the neck, chest, and arms. And finally we thank the patient for granting permission to publish this information.
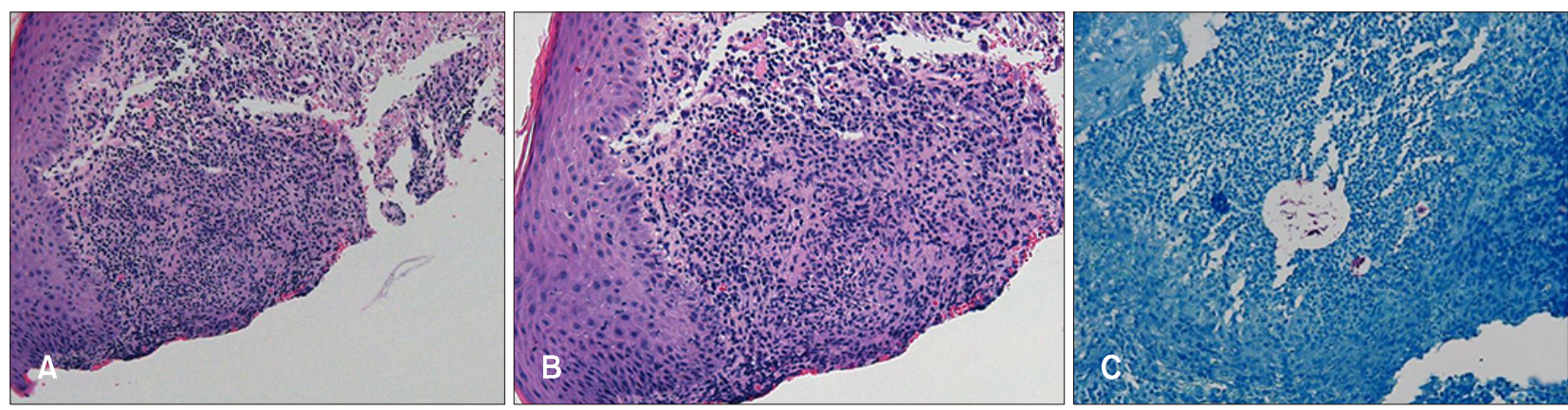

Fig. 2. (A, B) Granulomatous inflammation, in dermis and subcutaneous tissue (H\&E: $A, \times 100 ; B, \times 200)$. (C) Numerous acid-fast bacilli, in the acid-fast bacilli staining $(C, \times 200)$.

from many environmental sources ${ }^{2} . M$. chelonae infection has been linked to some cosmetic procedures, and also can colonize skin wounds, such as hidradenitis suppurativa lesions ${ }^{2}$. Cutaneous $M$. chelonae infection may be presented with diverse manifestations such as a chronic, non-healing cellulitis or skin ulcers ${ }^{3}$.

There is a case report of cutaneous atypical mycobacterial infection, in a body scrubber in Korean literature ${ }^{4}$. That case involved a person whose occupation was "body scrubber" but our case infection was initiated and disseminated, by body scrubbing. Nevertheless, the two cases are similar in that cutaneous atypical mycobacteria infection may occur, associated with water-related environmental sources without typical trauma history.

In our case, the patient had regularly scrubbed her body with an abrasive scrub towel while bathing. Body scrubbing may cause the disruption of epidermal barrier and small abrasions, that could be portals of entry for mycobacteria. M. chelonae could have been inoculated, through such abrasions during body scrubbing while bathing. Also, due to the decrease and loosening of dermal collagen by the aging process, we speculate that after the organism was inoculated into the neck, it may have spread in the tissue very slowly, from the neck to the arm due to scrubbing and advanced to its disseminated form.
We report an interesting case of cutaneous $M$. chelonae infection caused by body scrubbing. Clinicians should be mindful that even a minor skin injury caused by body scrubbing, may trigger inoculation and spreading of mycobacterium in the tissue especially among the elderly.

\section{CONFLICTS OF INTEREST}

The authors have nothing to disclose.

\section{ORCID}

Jee Yon Shin, https://orcid.org/0000-0003-0657-2416 Dae Hwi Eun, https://orcid.org/0000-0001-5057-7199 Ji Yeoun Lee, https://orcid.org/0000-0001-9269-6591 Tae Young Yoon, https://orcid.org/0000-0001-6947-1853

\section{REFERENCES}

1. Bhambri S, Bhambri A, Del Rosso JQ. Atypical mycobacterial cutaneous infections. Dermatol Clin 2009;27:63-73.

2. Gonzalez-Santiago TM, Drage LA. Nontuberculous Mycobacteria: skin and soft tissue infections. Dermatol Clin 2015; 33:563-577.

3. Schmidt AN, Zic JA, Boyd AS. Pedicure-associated Myco- 
bacterium chelonae infection in a hospitalized patient. J Am

Acad Dermatol 2014;71:e248-e250.

4. Yoo JS, Huh JW, Kim MS, Jue MS, Choi KH, Park HJ.
Cutaneous atypical mycobacterial infection in a body scrubber (“Ddaemirri"). Korean J Dermatol 2017;55:156-157.

\title{
A Case of Recalcitrant Erythema Nodosum Associated with Pancreatic Cancer
}

\author{
In Soon Jung, Sook Jung Yun, Jee-Bum Lee, Seung-Chul Lee, Young Ho Won \\ Department of Dermatology, Chonnam National University Medical School, Gwangju, Korea
}

\section{Dear Editor:}

A 56-year-old female presented with erythematous nodules on arms and legs, which first appeared on legs two weeks prior (Fig. 1). The patient had not previously experienced similar symptoms. She had no specific medication, medical, or family history and showed no systemic symptoms. Routine blood examination showed no specific findings. Skin biopsy showed fibrous interlobular septum with widening and septal infiltrate by inflammatory cells, including histiocytes, lymphocytes, and eosinophils. Infiltrate extended to adjacent fat lobules near the septa. Von Kossa stain was negative (Fig. 2). Although the patient was administered pentoxyfylline, colchicine, zaltoprofen and prednisolone $(10 \mathrm{mg} /$ day), the number of lesions continued to increase (Fig. 1). Further investigations were conducted to identify the reason for treatment resistance. Laboratory tests showed an increase in lipase $(14,139 \mathrm{U} / \mathrm{L}), \alpha$-fetoprotein $(829.9 \mathrm{IU} / \mathrm{ml})$, and carbohydrate antigen 19-9 (86.08 $\mathrm{U} / \mathrm{ml}$ ). Abdominal computed tomography showed malignant pancreatic cancer with metastasis to the liver and kidneys. The prednisolone dose was increased to $40 \mathrm{mg} /$ day, but there was no improvement. She died of tumor lysis syndrome 5 days after diagnosis of malignancy
Erythema nodosum (EN) can be idiopathic or secondary to infection, medication, inflammatory disease, or malignancy ${ }^{1}$. Although majority of cases associated with malignancy have been reported in relation to hematologic malignancies ${ }^{2}$, there are rare reports of EN secondary to solid tumors, such as lung cancer, colon cancer, and parathyroid cancer. Cases associated with pancreatic cancer are especially rare $^{3,4}$. We were unable to find any reported cases of EN in pancreatic cancer patients in Korean literature. In the present case, the patient had no factors except pancreatic cancer that could have caused EN. Moreover, the patient developed EN at 56-year-old and showed no improvement in spite of over 2 months of appropriate treatment. There is no clear difference in clinicopathological features between idiopathic and paraneoplastic EN. It is difficult to distinguish between these two states by morphologic findings and distribution pattern. The most helpful clue is disease course and response to treatment. Paraneoplastic EN shows poor response to treatment and relapses more frequently than idiopathic EN. Chowaniec et al. ${ }^{1}$ reported that malignancy must be considered as a cause of EN in cases with clinical symptoms such as weight loss, age over 50 years and poor response to treatment. In pancreatic

\footnotetext{
Received March 13, 2019, Revised May 7, 2019, Accepted for publication June 1, 2019
}

Corresponding author: Young Ho Won, Department of Dermatology, Chonnam National University Medical School, 42 Jebong-ro, Dong-gu, Gwangju 61469, Korea. Tel: 82-62-220-6681, Fax: 82-62-222-4058, E-mail: yhwon@jnu.ac.kr ORCID: https://orcid.org/0000-0003-4640-4337

This is an Open Access article distributed under the terms of the Creative Commons Attribution Non-Commercial License (http://creativecommons.org/licenses/by-nc/4.0) which permits unrestricted non-commercial use, distribution, and reproduction in any medium, provided the original work is properly cited.

Copyright $($ The Korean Dermatological Association and The Korean Society for Investigative Dermatology 